University of Wollongong

Research Online

Faculty of Engineering and Information

Faculty of Engineering and Information

Sciences - Papers: Part A

Sciences

January 2014

Behavioral characterization of electric vehicle charging loads in a distribution power grid through modeling of battery chargers

Ahmed Haidar

University of Wollongong, ahaidar@uow.edu.au

Kashem M. Muttaqi

University of Wollongong, kashem@uow.edu.au

Follow this and additional works at: https://ro.uow.edu.au/eispapers

Research Online is the open access institutional repository for the University of Wollongong. For further information contact the UOW Library: research-pubs@uow.edu.au 


\title{
Behavioral characterization of electric vehicle charging loads in a distribution power grid through modeling of battery chargers
}

\author{
Abstract \\ Plug-in Electric Vehicle (PEV) is a new atypical load in power systems. In future, PEV load will play a \\ significant role in the distribution grids. This integrated load into the power grid may overload the system \\ components, increase power losses and may violate system constraints. Currently, the most common \\ method of Electric Vehicle (EV) modeling is to consider the EV loads as constant power elements without \\ considering the voltage dependency of EV charging system during state of charges (SOC). EV load \\ demand cannot be considered as a constant power, as modeling as a constant power load will not \\ provide accurate information about the behavior of charging system during charging process. As several \\ research projects on smart grids are now looking into realistic models representing the realistic behavior \\ of an EV loads, this paper proposes a methodology for modeling of EV charger integrated to an electricity \\ grid in order to understand the impacts of EV charging load. A charging system was designed to capture \\ the EV load behavior and extract the coefficients of the EV ZIP load model. A comparative study was \\ carried out with different types of load models. The results indicate that the assumptions of load demand \\ as a constant power to analysis the effect of PEVs on power grid would not be effective in real time \\ application of PEVs.
}

\section{Keywords}

electric, vehicle, charging, loads, distribution, power, grid, modeling, battery, chargers, characterization, behavioral

\section{Publication Details}

A. Haidar \& K. M.. Muttaqi , "Behavioral characterization of electric vehicle charging loads in a distribution power grid through modeling of battery chargers," in 2014 Industry Applications Society Annual Meeting (IACC 2014), 2014, pp. 1-8. 


\section{Behavioral Characterization of Electric Vehicle Charging Loads in a Distribution Power Grid through Modeling of Battery Chargers}

\author{
Ahmed M. A. Haidar \\ Member, IEEE \\ University of Wollongong \\ SECTE, 2522, NSW, Australia \\ ahaidar@uow.edu.au
}

\author{
Kashem M. Muttaqi \\ Senior Member, IEEE \\ University of Wollongong \\ SECTE, 2522, NSW, Australia \\ kashem@uow.edu.au
}

\begin{abstract}
Plug-in Electric Vehicle (PEV) is a new atypical load in power systems. In future, PEV load will play a significant role in the distribution grids. This integrated load into the power grid may overload the system components, increase power losses and may violate system constraints. Currently, the most common method of Electric Vehicle (EV) modeling is to consider the EV loads as constant power elements without considering the voltage dependency of EV charging system during state of charges (SOC). EV load demand cannot be considered as a constant power, as modeling as a constant power load will not provide accurate information about the behavior of charging system during charging process. As several research projects on smart grids are now looking into realistic models representing the realistic behavior of an EV loads, this paper proposes a methodology for modeling of $\mathrm{EV}$ charger integrated to an electricity grid in order to understand the impacts of EV charging load. A charging system was designed to capture the EV load behavior and extract the coefficients of the EV ZIP load model. A comparative study was carried out with different types of load models. The results indicate that the assumptions of load demand as a constant power to analysis the effect of PEVs on power grid would not be effective in real time application of PEVs.
\end{abstract}

Index Terms-- Plug-in electric vehicle; EV load modeling, Battery charger, Battery state of charge

\section{INTRODUCTION}

With the expected growth of Plug-in Electric Vehicles (PEVs) over the coming years, the load behavior of EV charging system becomes an important area of research. There is an evidence of a dramatic increase in the number of Electric Vehicle (EVs) for domestic use in Australia [1]. In order to make EV as a feasible alternative to conventional petrol-driven vehicle, it is crucial to develop smart battery chargers.

In particular, battery chargers can produce effects on low voltage distribution systems. Although these effects are small in a distribution system from a view of a single EV owner, however there are a large number of EVs that may be charged at the same time from a distribution grid and hence deleterious effects in an entire distribution system can be highly significant. Therefore, it is necessary to develop an effective EV load model to investigate the impacts that charging of PEVs can have on the security and operation of distribution grids [2].
Load model is a set of equations represented the mathematical relationship between a bus voltage magnitude and frequency at a given bus-bar and the (active and reactive) power or the current flowing into the load of the same bus. Two typical load models, which are well developed and applied, are static load model and dynamic load model. While the relationship in static load model is described by algebraic equations, differential equations are used instead to represent the dynamic behavior of the system in dynamic load model $[3,4]$. Typically, loads are modeled as purely static functions of voltage and frequency in which the per unit voltage variation is much larger than the per unit frequency variation. It should be noted that, in fact, load can be broadly categorized into two categories: one category in which electrical power is independent of frequency, such as lighting, heating or any pure resistive loads, and the other category in which electrical power is dependent on frequency, such as motor, fans or any inductive loads. Thus, in a composite load bus, the change in electrical power is not equal to the initial change in load power, but a part of load that varies with the changing of frequency [5].

There are two types of battery chargers which are off-board charger and on-board charger. Off-board charger can be separated from the EV and can be compared to a petrol station aimed to have a fast charge. On-board charger is combined with the EV and can be separated from the driving system or combined with the inverter connected to drive motor [6] and would be appropriate for slow charge using a household power outlet during night times, when demand for electricity is low.

In many designs and studies related to EV battery chargers, the EV battery loads are considered as a static load and the realistic system behavior of the batteries during charging process have been ignored. Indeed, the energy consumption by an EV is a function of not only the terminal voltage but also other variables governed by the battery state of charge (SOC) due to the changes in charging rate. Furthermore, the voltage dependency of the charging system is a function of SOC and this can cause different load characteristics for different SOC levels [7]. As a result, there is a necessity to characterize the dynamics of the EV loads due to battery charging considering different SOC levels. The upcoming 
reality of smart grids will require studies and developments to alleviate the above-mentioned problems and aiming for effective integration of EVs to the grids. With this target, the work covered in this paper is to investigate the realistic effects of EV load model on system losses and bus voltages or voltage profile. The rest of the paper is organized as follows: Section 2 provides a review of the battery charger topologies targeting to single-phase on-board battery chargers, including their design philosophy and modeling aspects. The battery charging profiles and charging systems are discussed in Section 3 including the ZIP load model. The results are outlined in Section 4. Finally conclusion is given in Section 5.

\section{ON-BoARD BATtery ChARgers, THEIR DESIGN PhILOSOPHY AND MOdELING ASPeCTS - A ReVIEW}

In the recent years, there are significant research contributions in the field of PEV integration into the power grids. Though the results from these various contributions are promising, unfortunately the EV load is modeled as constant power load in most of these studies. This model is a simple model in which the active and reactive loads are treated as independent of voltage magnitude. Since EV Charging systems will be integrated in the existing distribution systems near future, accurate load model that reliably reflects underlying phenomena of the physical loads give better tuning of the control operation. Therefore, the use of correct load models is vital to ensure the appropriate design deployment and improved operational conditions [8]. In the previous bibliography on PEVs [9-13], load model considers the variation of the distribution system supply parameters, but the general case for the load model is that the distribution system affects the EV loads and the EV loads have an effect on the distribution system measurement.

Modeling of EV load for system studies requires an accurate understanding of its battery profile and charging characteristics. Thus, the design of EV battery chargers with proper charging algorithms is essential to meet the regulatory requirements for the quality of the charging voltage and current. Currently, all chargers in the market employ unidirectional chargers with traditional charging methods consist of constant current (CC), constant voltage (CV) [14]. A typical block diagram of an EV on-board battery charger is shown in Fig. 1 which illustrates the two converters; AC-DC converter with Power Factor Correction (PFC) [15, 16] followed by an isolated DC-DC converter, with input and output electromagnetic interference (EMI) filters.

A key component of the charging system is the front-end AC-DC converter. Full-bridge topology with conventional boost converter for PFC applications is the most popular ACDC converter topology used in the $1-5 \mathrm{~kW}$ range [17]. However, the potential applications of a single phase twoswitch buck type AC-DC Converter topology with inductor voltage control appears to be a good candidate for high current battery charging applications, when used as a PFC converter due to the fact that the $\mathrm{CC}$ and $\mathrm{CV}$ type battery charging characteristics can be easily implemented [18]. A variety of circuit topologies, and control methods have been developed for PEV battery chargers [15, 19-25]. Single-stage AC-DC power conversion where the low frequency ripple is large in the output current is only suitable for lead acid batteries. On the other hand, the two-stage AC-DC/DC-DC power conversion provides inherent low frequency ripple in the output current. Hence, the two-stage approach is preferred where the power rating is relatively high for batteries requiring low voltage ripple such as lithium-ion batteries [23].

Knowing that charging time and battery life are linked to the characteristics of the battery charger, adequate care must be paid to the charger. The conventional boost topology charger is the most popular topology for PFC applications. In this topology, the output capacitor ripple current and the inductor volume become a problematic design issue at high power. Therefore, this topology is good for power range below $1 \mathrm{~kW}[15,23]$. Significant study outcomes related to single phase charger models are given in [15-25]. Based on a wide ranging study of literature it has been found that flyback converter operating in discontinuous current mode is the preferred topology [22]. In this topology of EV chargers, the input current is directly proportional to the input voltage, and since the circuit on average is seen as a resistive load on the AC supply side, with a careful design of such topology, the electrolytic capacitors can be eliminated [26]. The interleaved unidirectional charger topology based on bridgeless boost PFC topology avoids the need for the rectifier input bridge [23]. Generally, interleaving with input bridge has been also proposed to reduce battery charging current ripple and inductor size for power levels up to $3.5 \mathrm{~kW}$ $[15,23]$. However, this topology must provide heat management for the input bridge rectifier [16].

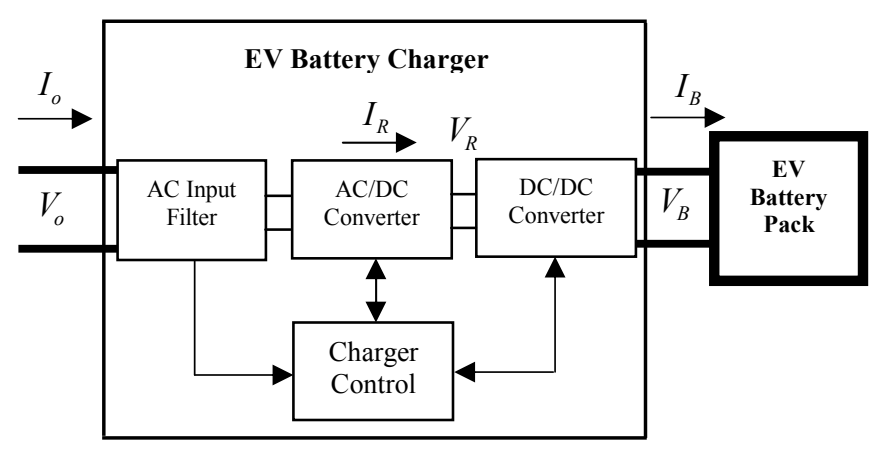

Fig. 1. Block diagram of a common battery charger

The operation of an EV battery charger depends on components and the control strategies employed. Referring to Fig. 1, in the first stage of control, sensing circuits provide the status of all relevant system variables required for control the algorithm as feedback signals. The control algorithm is responsible in achieving high-level steady-state and transient performance. The reference values of variables along with sensed values are used in the third stage of the control 
strategy to derive the gating signals for the controllable switches of the converters. Today, all of the current EVs available in the market still use conventional unidirectional chargers whose first stage is a diode bridge rectifier [14, 16]. Due to time varying nature of voltage and/or current of ACDC converters, it is practically difficult to design controllers for single phase chargers with control gains selected for fundamental frequency. Thus, different types of controlling strategies have been proposed and available in the literature and some of them are available in practice for single-phase conveners with different control strategies [27].

Currently, most PEVs use a single-phase on-board charger and many circuit configurations for single-phase EV battery charger with various topologies and control schemes are reported in the literature $[14,15]$. In [24] a single stage integrated converter is proposed based on direct $\mathrm{AC} / \mathrm{DC}$ conversion theory which is suitable for Levels 1 (120-230 VAC, 1-phase) and 2 (240-400 VAC 1- or 3-phase) charging [16]. This converter is controlled using a hysteresis control and the design reduces the number of semiconductor switches and high current inductors. A four-leg bidirectional EV battery charger has been investigated for charge station applications in [20], where three legs are used for a single phase full-bridge-based Pulse Width Modulation (PWM) rectifier (AC-DC or DC-AC) during the battery charging/discharging operations. In this design, the PWM rectifier can compensate reactive and unbalanced active currents on single-phase three-wire distribution systems. The fourth leg is used as a bidirectional DC-DC converter for battery-charging and discharging. An improved single phase EV charger developed that is classified as an AC-DC controllable PFC Buck Converter with PWM switching uses self-commutating solid-state devices [21]. For the stability and optimum design of such a charger, the sizes of capacitor and inductor on the input filter in the buck converter are quite important for a proper response [22].

\section{MOdELING OF EV CHARGING LOAD}

Lithium-Ion chemistry possesses many features that may make them attractive for EV applications. The practical charging characteristic curves of a Lithium battery are depicted in Fig. 2 [28]. As seen from this Figure, after reaching a certain SOC, the voltage becomes constant and the current gradually reduces as the battery reaches its maximum charge. Although the charging profiles in this figure are obtainable with laboratory experimentation, the battery chemistries and battery management system of the various EVs are different. Thus, the same profiles are not always valid because different charging strategies can be applied depending on the battery type [29] and this will affect the demand profile on the grid side. Note that batteries of the same type can present a different charging profile because of the difference in the chemical structure and manufacturer policies.

\section{A. EV Charging Profiles}

For device with a control loop that cycles the on and off, the energy consumed by this device is a function of the supply voltage and the length of time it is on. When the supply voltage to the device is lowered, the energy consumed changes. Therefore, a collection of constant elements (impedance, current and power) in a ZIP model is used to model the voltage response of a device [8]. Similarly, the energy consumption by an EV is a function of battery voltage at different ranges in SOC due to the changes in charging rate. This can potentially cause different load characteristics for different SOCs.

As seen from Fig. 1, when the EV charged from the grid side (Grid to Vehicle), the charger is supplied with grid voltage $V_{o}$ and absorbs the current $I_{o}$. On the battery side, $V_{B}$ and $I_{B}$ identify the terminal voltage and the current absorbed by the battery. Referring to Fig. 2, it is clear that the voltage is a function of the SOC which is defined as,

$$
S=\frac{C h}{C h_{\text {nom }}}
$$

where, $S$ : state of charge; $C h$ : the actual stored "Ah" capacity in the battery; $C h_{\text {nom }}$ : the nominal "Ah" capacity of the battery. The battery terminal voltage $V_{B}$ is determined by the battery dynamic parameters. It depends on the battery SOC and its impedance. As for the battery charging current $I_{B}$, it is evaluated through the battery management system by monitoring the battery voltage, SOC and the battery temperature $[7,30]$. During charging process, the active and reactive powers on the grid side can be calculated by Eqs. (2) and (3),

$$
\begin{gathered}
P_{o}(S)=V_{o} I_{o} \cos \varphi(S) \\
Q_{o}(S)=V_{o} I_{o} \sin \varphi(S)
\end{gathered}
$$

The charger control of the DC-DC converter maintains the difference between the $I_{B}$ and the reference charging current. The governing equation of the rectified voltage $V_{R}$ in the DCDC buck converter as shown in Fig. 3 is given below,

$$
V_{R}=V_{B}+L_{2} \frac{d I_{L_{2}}}{d t}
$$

where,

$$
I_{L_{2}}=I_{B}+C_{2} \frac{d V_{B}}{d t}
$$

Considering the efficiency " $\eta$ " of the charger, the power on the DC side of battery charger at different levels of charging, can be expressed as, 


$$
P_{B}(S)=\eta\left[V_{o} I_{o} \cos \varphi(S)\right]
$$

A seen from the above equations, the system voltage dependency of the charging is a function of SOC. This system is not linear and can cause different load characteristics for different SOC levels. In the following subsection, time domain simulation is used to evaluate the performance of the above model.

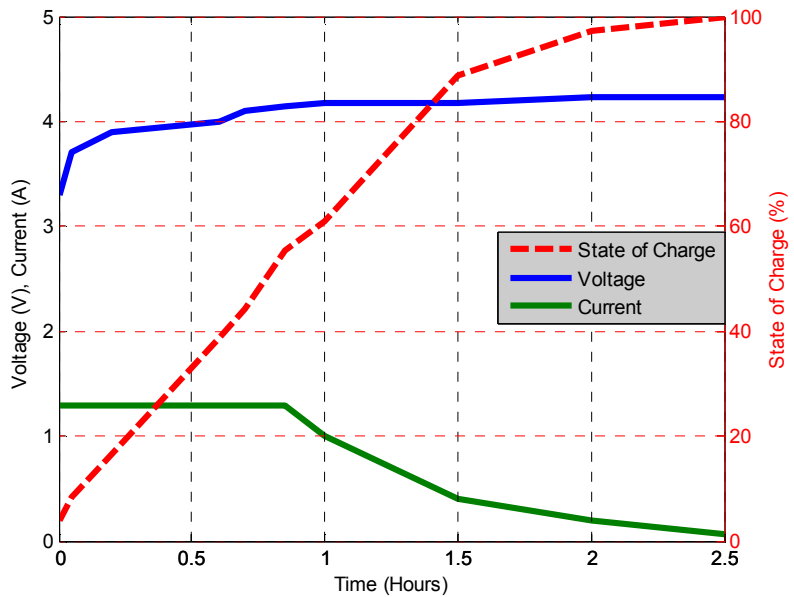

Fig. 2. An example of charging characteristic of a lithium battery

\section{B. $\quad$ Simulating Models for ZIP Values}

The single phase charger used in this study is composed of a fully controllable AC-DC converter with an input AC filter and a DC-DC buck converter [21, 22] as shown in Fig. 3. For this charger, the controller used is modified and shown in Fig. 4. $\mathrm{L} 1$ and $\mathrm{C} 1$ form the $\mathrm{AC}$ side filter, whereas $\mathrm{L} 2$ and $\mathrm{C} 2$ are used to reduce the high frequency ripple on the DC side. The current paths through the converter are listed in Table I. The charger operates as a buck converter during charging mode and the flow of charge is controlled by the switches operating at high frequency. On the $\mathrm{AC}$ side, the main component to shape the input current is L1.

In order to illustrate how the component parameters and system variables change with different levels of SOC, the EV charging system in Fig. 3 was simulated using MATLAB. A Lithium-Ion battery is modeled using the EV battery model given in [30]. The nominal capacity of a battery pack is $60 \mathrm{Ah}$ with a nominal voltage of $280 \mathrm{~V}$ and the charger is fed from $230 \mathrm{~V}, 50 \mathrm{~Hz}$ grid system. The general algorithm of a battery charger with a closed loop control in the CC charging mode is such that, the battery is provided a high charging current until the battery voltage reaches a certain voltage level. After this threshold is reached, the charging is switched to $\mathrm{CV}$ charging mode where the battery is charged with a trickle current until the upper threshold voltage is maintained across the battery. During the charging process, the current and voltage error signals which are the differences between the measured and reference values are calculated to generate the switching frequencies, where the direct duty cycle can be calculated using Eq.(7) [31].

$$
d(t)=\frac{K_{P I}\left[\sin \left(\omega_{i n} \Delta t\right)\right]-i_{a c}(t)}{K_{s}}+\frac{V_{r e f}-V_{d c}(t)}{V_{r e f}}
$$

where, $K_{s}=T_{s} V_{\text {ref }} / L_{2} ; T_{s}$ : switching period; $\omega_{i n}$ : AC line frequency; $\Delta t$ : change in time; $V_{r e f}:$ reference DC voltage; $K_{P I}:$ the output of the PI controller; $i_{a c}:$ AC input current.

Fig. 5 shows the active and reactive powers drawn by the charger as a function of SOC including the battery voltage, while Fig. 6 shows the DC current of the charger and the battery voltage during charging process. It can be noted that the current drawn by the battery is reduced after the SOC level is reached to $90 \%$, whereas the battery voltage continues to increase near to the cutoff condition. Fig. 7 shows the response of the battery voltage, charging current and state of charge for a sudden decrement of $20 \%$ in the input voltage.

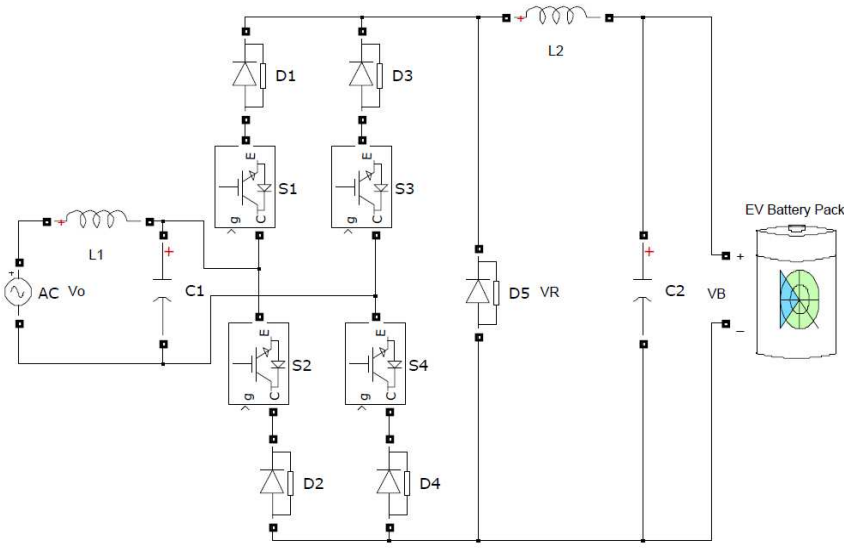

Fig. 3. Interface scheme of EV charging system

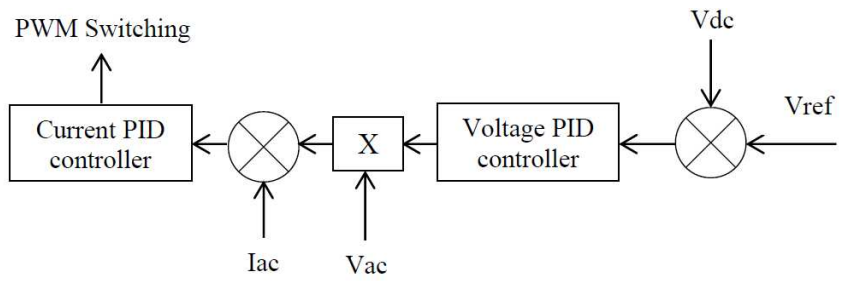

Fig. 4. Schematic of the modified controller

TABLE I

\begin{tabular}{|c|c|c|c|}
\hline $\begin{array}{l}\text { Charging } \\
\text { Modes }\end{array}$ & $\begin{array}{l}\text { Conducting } \\
\text { Active } \\
\text { switches }\end{array}$ & $\begin{array}{c}\text { State of } \\
\text { current path } \\
\text { through } \\
\text { switches } \\
\end{array}$ & $\begin{array}{l}\text { Battery Power } \\
\text { flow }\end{array}$ \\
\hline \multirow{2}{*}{$\begin{array}{l}\text { Mode } 1 \\
\text { Positive } \\
\text { half cycle }\end{array}$} & S1-D1 & ON & \multirow{2}{*}{$\begin{array}{l}\text { Transferred from } \\
\text { AC source }\end{array}$} \\
\hline & S4-D4 & $\mathrm{ON}$ & \\
\hline \multirow{2}{*}{$\begin{array}{l}\text { Mode } 2 \\
\text { Negative } \\
\text { half cycle }\end{array}$} & S2-D2 & ON & \multirow{2}{*}{$\begin{array}{l}\text { Transferred from } \\
\text { AC source }\end{array}$} \\
\hline & S3 D3 & $\mathrm{ON}$ & \\
\hline \multirow[t]{2}{*}{$\begin{array}{l}\text { Mode } 3 \\
\text { Full cycle }\end{array}$} & $\begin{array}{l}\text { S1-D1 } \\
\text { S4-D4 } \\
\text { S2-D2 } \\
\text { S3 D3 } \\
\end{array}$ & OFF & \multirow{2}{*}{$\begin{array}{l}\text { Transferred from } \\
\text { stored energy in } \\
\text { the DC } \\
\text { conductor (L2) }\end{array}$} \\
\hline & D5 & ON & \\
\hline
\end{tabular}

SWITCHING MODE FOR CURRENT PATHS OF CONVERTER 


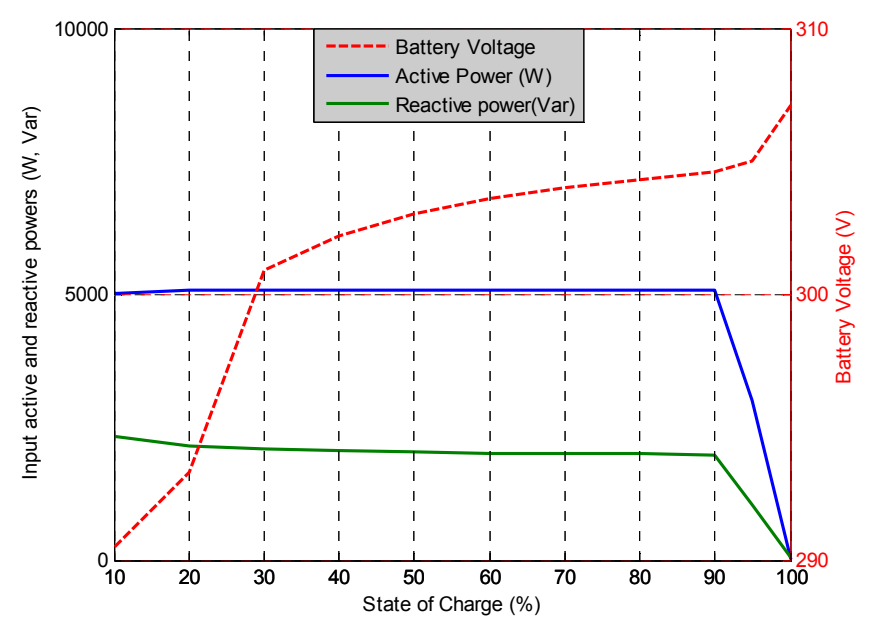

Fig. 5. Battery voltage, and Active and reactive powers drawn by the

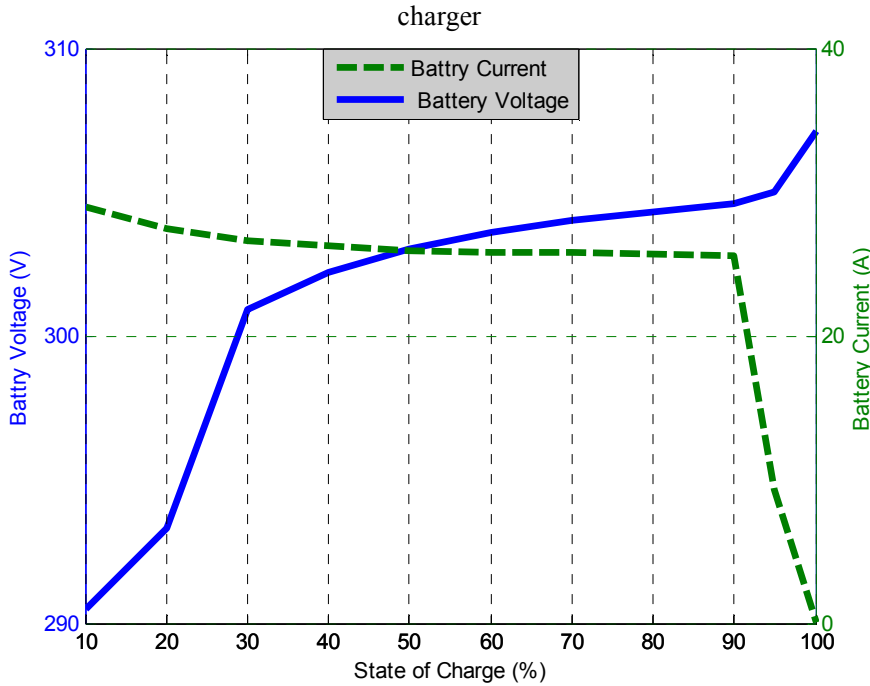

Fig. 6. Battery voltage and average current as a function of SOC

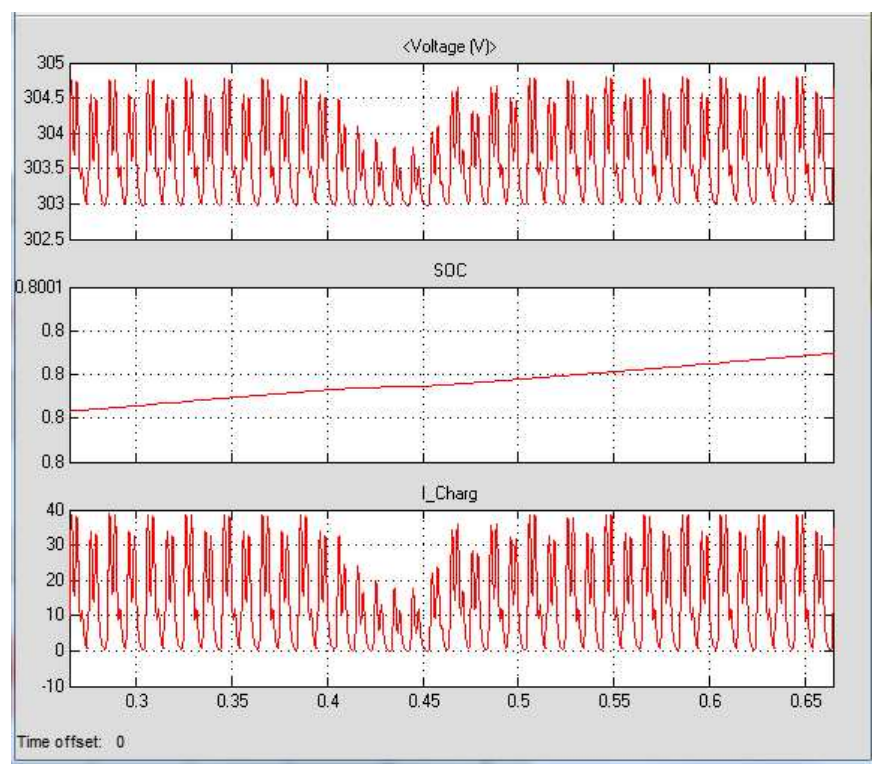

Fig. 7. Response of charging system for a sudden change in the input voltage

\section{EV LOAD MODELING IN DisTRIBUTION SYSTEM}

A set of $I_{B}$ and $V_{B}$ values for a range of SOC $(10 \%-100 \%)$ at different voltage levels of $V_{o}(180 \mathrm{~V}-230 \mathrm{~V})$ are obtained through simulation using the EV charging system described in the previous subsection, while active and reactive powers consumed from the AC side are recorded at each level of voltage and SOC. These recorded values are used to identify the voltage dependent nature of EV load for different level of SOC. The next step was to determine the ZIP values that produced a best fit approximation to the recorded values utilizing a constrained least squared to find the EV ZIP values. Once the best fit ZIP values are found, they could be used in the following ZIP equations [32],

$$
\begin{aligned}
& P_{Z I P}=P_{o}\left(Z p\left(\frac{V}{V_{o}}\right)^{2}+I p\left(\frac{V}{V_{o}}\right)+P p\right) \\
& Q_{Z I P}=Q_{o}\left(Z q\left(\frac{V}{V_{o}}\right)^{2}+I q\left(\frac{V}{V_{o}}\right)+P q\right) \\
& Z p+I p+P p=Z q+I q+P q=1
\end{aligned}
$$

where $P_{o}, Q_{o}$ are the active and reactive load powers obtained from Eqs (2) and (3) at rated voltage $V_{o} ; V$ is the actual voltage magnitude; $Z p, I p, P p$ are the constant impedance, constant current and constant power fractions of the active EV load; $Z q, I q, P q$ are the constant impedance, constant current and constant power fractions of the reactive EV load.

In General form, for a bus " $\mathrm{k}$ " of a system with "N" number of buses as depicted in Fig. 8, the active and reactive power balance equations can be written as:

$$
\begin{gathered}
P_{d k}=P_{s}-P_{k} \\
Q_{d k}=Q_{s}-Q_{k}
\end{gathered}
$$

where $P_{s}$ and $Q_{s}$ are the active and reactive power source; $P_{d k}$ and $Q_{d k}$ are the active and reactive power loads at bus "k" which are given in Eqs. (8) and (9), respectively. $P_{k}$ and $Q_{k}$ are the active and reactive power injected into the system and computed by,

$$
P_{k}=V_{k} \sum_{i=1}^{n} Y_{k m} V_{m} \cos \left(\delta_{k}-\delta_{m}-\theta_{k m}\right)
$$




$$
Q_{k}=V_{m} \sum_{i=1}^{n} Y_{k m} V_{m} \sin \left(\delta_{k}-\delta_{m}-\theta_{k m}\right)
$$

where $V_{k}$ and $V_{m}$ are bus voltage magnitudes at buses " $k$ "and "m", with their respective phase angles $\delta_{k}$ and $\delta_{m}$; $Y_{k m}$ and $\theta_{k m}$ are the magnitude and angle of the branch " $\mathrm{km}$ " entry in the Y-bus matrix; and " $\mathrm{N}$ " is the total number of buses in the system. The bus voltages are found by solving the above mismatch equations. In this work, Newton-Raphson method was used to solve a set of mismatch equations with the constant power and ZIP load models for the IEEE 69 test system as shown in Fig. 9 [33]. This system has been selected as a case study to evaluate the effect of load modeling due to PEVs. Load flow solutions for the distribution system were obtained by embedding the EV ZIP load model in the loadflow algorithm. In the power flow calculation for the ZIP model, the active and reactive loads are continuously updated to reflect the changes in the bus voltages. The base case data of the system as given in Fig. 9 were used to test the developed ZIP model and to observe the effects of various load models on the power flow results.

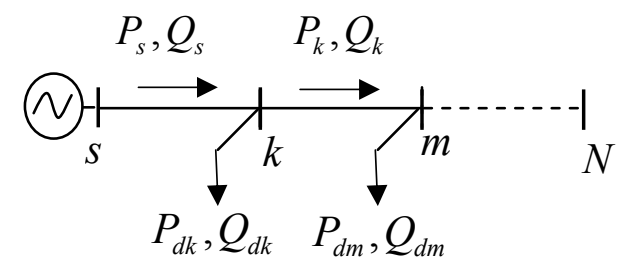

Fig. 8. System with "N" number of buses

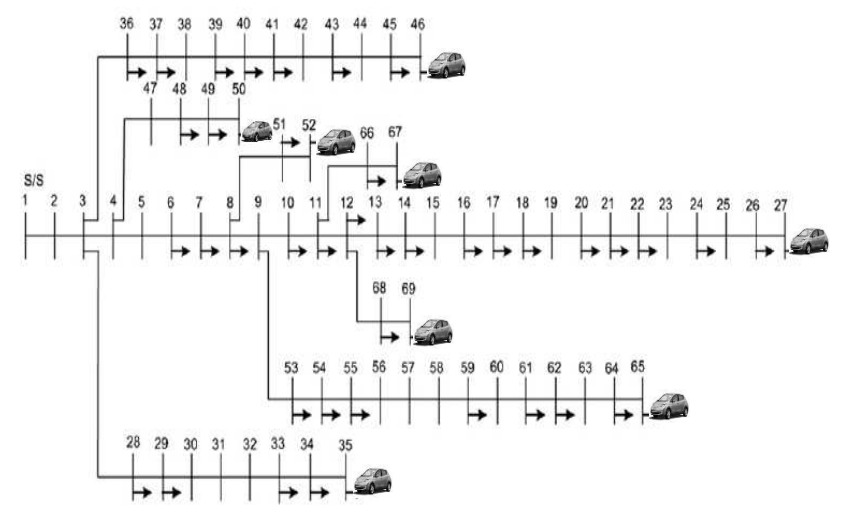

Fig. 9. IEEE 69 bus distribution system with PEV

\section{RESULTS AND DISCUSSION}

The impact of charging on the distribution system is demonstrated by computing the voltage deviations and the power loss for each EV load model. Voltage deviation can be defined as the difference between the nominal and the actual voltages. In solving the power flow problem, for all models, the source voltage (root bus) was used as 1.0 per unit with a tolerance of $0.01 \%$. In the analysis, from the base loads as given in the IEEE 69 test system, two cases have been considered. In the first case, a $25 \%$ of the base loads in all buses were considered as EV loads while in the second case, a $50 \%$ of the base loads were considered as EV loads. It was also assumed that the EV loads are distributed equally in load buses of the IEEE 69 test system.

Fig. 10 depicts the voltage deviations obtained using various load models. The highest voltage was observed on bus 65 . Additionally, among the various load models, the constant power model provides the highest voltage deviation whereas the constant impedance model gives the lowest voltage deviation, due to the fact that the constant impedance represents lower loads to the system than the constant power. The same fact can be noted in Table 2 and 3 . These tables illustrate the values of active and reactive system load with the power losses of distribution system for various load models. Compared to the constant power load model, the loads of the system for the ZIP model, constant impedance and constant current are reduced. Similarly, a reduction of power losses for the ZIP model, constant impedance and constant current can be seen in the fourth and fifth columns of Table 2 and 3. This reduction is because of the lower load and slightly higher voltage profile which is updated during the power-flow. Furthermore, the constant impedance is more sensitive than the constant current model. However, the constant power load is not responsive and this is obvious because the constant power model is independent of voltage. The same behavior was also observed for the reactive system load. The difference in power demand and loss between the ZIP and constant power models is graphically shown in Figs. 11. These results are directly related to Tables 2 and 3. The reason of the differences in the power losses, as seen from Figure 11, is that the power of the constant impedance and constant current of the polynomial function is voltage dependent, whereas in the constant power model, power demand remained constant. Thus, in the case of high EV penetrations, the power losses represented by the constant model will be increased significantly.

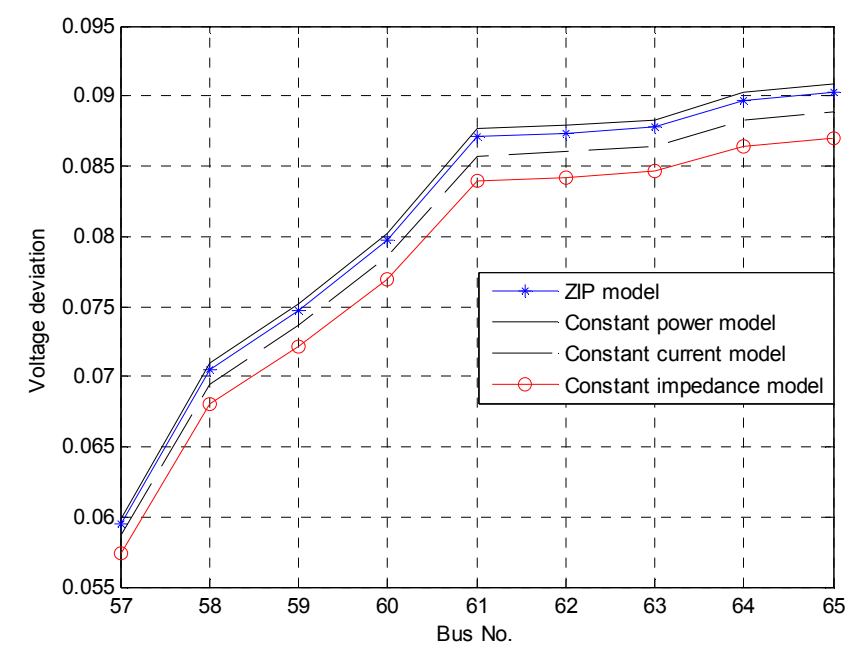

Fig.10. Voltage deviation of some monitored buses for various load models 
TABLE II

\begin{tabular}{lcccc} 
LOAD DEMAND AND LOSS FOR VARIOUS MODELS WHEN EV LOAD IS 50\% \\
\hline Load model & $\begin{array}{c}\text { Total } \\
\text { Active } \\
\text { load } \\
\text { (MW) }\end{array}$ & $\begin{array}{c}\text { Total } \\
\text { Reactive } \\
\text { load } \\
\text { (MVar) }\end{array}$ & $\begin{array}{c}\text { Total } \\
\text { active } \\
\text { loss } \\
\text { (MW) }\end{array}$ & $\begin{array}{c}\text { Total } \\
\text { reactive } \\
\text { loss } \\
\text { (MVar) }\end{array}$ \\
\hline Zip model & 3.788654 & 2.687434 & 0.222401 & 0.101029 \\
\hline $\begin{array}{l}\text { Constant } \\
\text { Power }\end{array}$ & 3.800401 & 2.693851 & 0.224948 & 0.102120 \\
\hline $\begin{array}{l}\text { Constant } \\
\text { Current }\end{array}$ & 3.758248 & 2.663443 & 0.215926 & 0.098255 \\
\hline $\begin{array}{l}\text { Constant } \\
\text { Impedance }\end{array}$ & 3.716046 & 2.633478 & 0.207481 & 0.094634 \\
\hline
\end{tabular}

TABLE III

LOAD DEMAND AND LOSSES FOR VARIOUS MODELS WHEN EV LOAD IS 25\%

\begin{tabular}{lcccc}
\hline Load model & $\begin{array}{c}\text { Total } \\
\text { Active } \\
\text { load } \\
\text { (MW) }\end{array}$ & $\begin{array}{c}\text { Total } \\
\text { Reactive } \\
\text { load } \\
\text { (MVar) }\end{array}$ & $\begin{array}{c}\text { Total } \\
\text { active } \\
\text { loss } \\
\text { (MW) }\end{array}$ & $\begin{array}{c}\text { Total } \\
\text { reactive } \\
\text { loss } \\
\text { (MVar) }\end{array}$ \\
\hline $\begin{array}{l}\text { Zonstant } \\
\text { Power }\end{array}$ & 3.798222 & 2.692576 & 0.224320 & 0.101852 \\
\hline $\begin{array}{l}\text { Constant } \\
\text { Current }\end{array}$ & 3.801516 & 2.694318 & 0.224948 & 0.102120 \\
\hline $\begin{array}{l}\text { Constant } \\
\text { Impedance }\end{array}$ & 3.780262 & 2.679219 & 0.220543 & 0.100233 \\
\hline
\end{tabular}

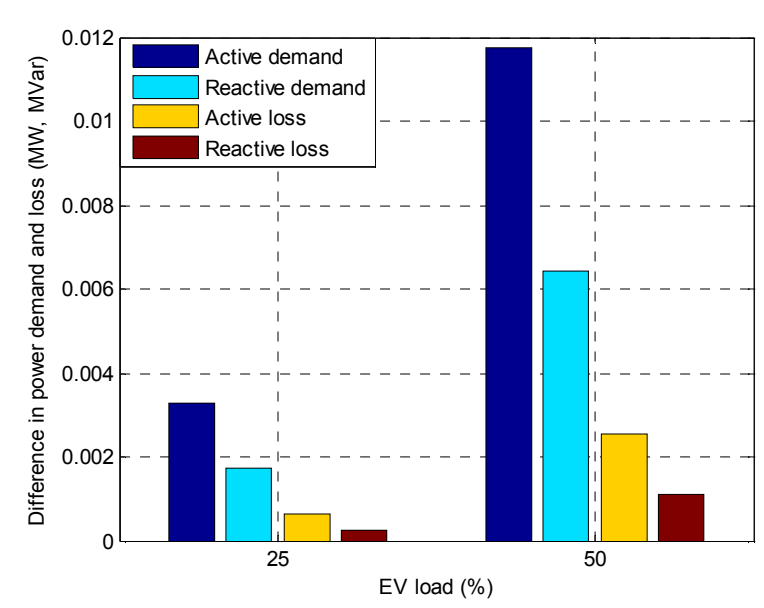

Fig.11. The difference in demand and loss between ZIP and constant power models

For further evaluation of ZIP load model, the impacts of EV charging loads on the line power flows have been measured by implementing the constant power and ZIP models. Table 4 lists the flow of power in some selected lines based on their locations in the test system. In general, the capacity of power flow will be increased when using constant power load model. As seen from Table 4, the flows of power in the lines are found to be higher in the constant load model for both cases (EV of $25 \%$ and EV of 50\%). Fig. 12 shows the differences in power flows between ZIP model and constant power models; the results in this figure are directly related to Tables 4 . These differences indicate that the ZIP model is representing less loads compare with the constant load model. Increasing the difference will cause a higher loss in the distribution system because of increasing the capacity of power flow in the lines when constant power model in used.

Because the EV charging load is incredibly growing in the power system, it is necessary to assess the true reflection of each load model. It can be evidently observed from Fig. 13 that due to the use of the constant power model, when EV loads are considered as $50 \%$ of the base loads, EV load in constant power load model represents higher power flow in the lines.

The results indicate the importance of using the ZIP model as this model reflects the true characteristics of the EV loads. The existence of exponential load models having wider range of ZIP coefficients of battery charger load have been already verified through laboratory testing [32].

TABLE IV

THE FLOW OF POWER IN SOME SELECTED LINES

\begin{tabular}{lcccc}
\hline \multirow{2}{*}{ Line number } & \multicolumn{2}{c}{ Constant power model } & \multicolumn{2}{c}{ ZIP model } \\
\cline { 2 - 5 } & $25 \%$ & $50 \%$ & $25 \%$ & $50 \%$ \\
\hline L3 (3-4) & 3.7496986 & 3.749698 & 3.7457787 & 3.733791 \\
\hline L7 (7-8) & 2.7962353 & 2.796235 & 2.7925669 & 2.781326 \\
\hline L10 (10-11) & 0.7476255 & 0.747625 & 0.7471226 & 0.745600 \\
\hline L27 (3-28) & 0.0915381 & 0.091538 & 0.0915364 & 0.091533 \\
\hline L35 (3-36) & 0.1857571 & 0.185757 & 0.1857521 & 0.185740 \\
\hline L46 (4-47) & 0.8507552 & 0.850755 & 0.8506633 & 0.850403 \\
\hline L52 (9-53) & 1.8564585 & 1.856458 & 1.8533983 & 1.843999 \\
\hline
\end{tabular}

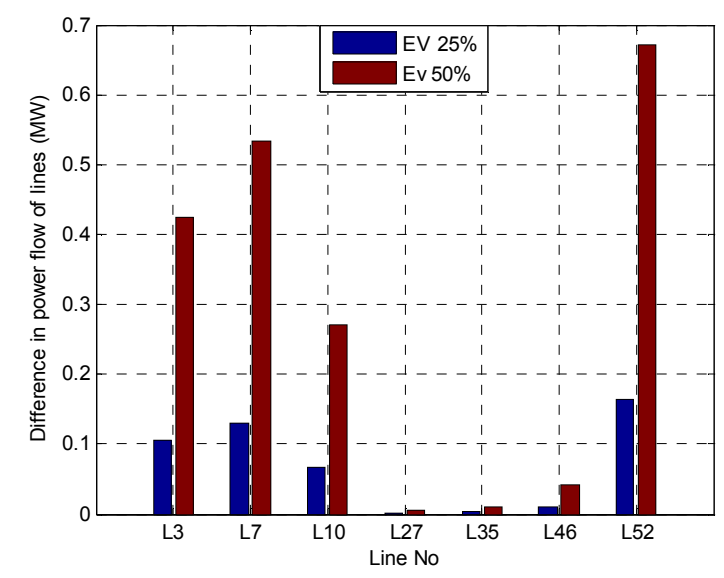

Fig.12. The differences in power flows between ZIP and constant models

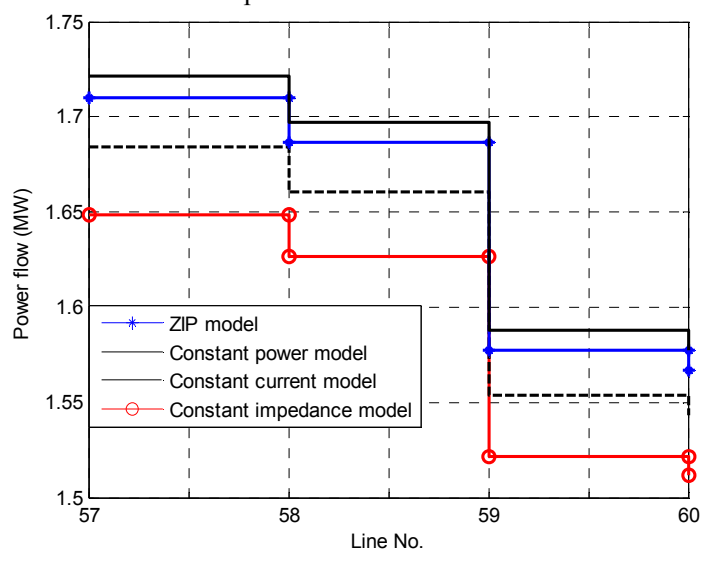

Fig.13. Power flows in some monitored lines for various load models 


\section{CONCLUSION}

In this paper, the modeling of EV charging load is addressed and different EV load models were studied through modelling of a Lithium-ion Battery Pack. The process for adaptation of EV load in distribution system is also presented so that the various load models can easily be incorporated and updated in the load flow iterations. It has been identified that the distribution loading margin is influenced by the EV load models. The results show that the power losses, bus voltages, and real and reactive power demands are lower when using the EV ZIP model compared with the constant power load model. Hence, it is important to choose the appropriate load model that is more suitable for a given system in order to obtain accurate results. As the assessment of load behavior is more complex especially for EV charging loads, the proposed methodology is crucial for a realistic system study in the context of future electricity grids. Therefore, the future work will be focusing on the incorporation of different charging systems including different types of batteries.

\section{REFERENCES}

[1] S. Speidel, F. Jabeen, D. Olaru, D. Harries, and T. Bräunl "Analysis of western Australian electric vehicle and charging station trials," 2012, Australian Transport Research Forum, Perth, pp. 1-12.

[2] J. Carlos Gómez, and Medhat M. Morcos, "Impact of EV Battery Chargers on the Power Quality of Distribution Systems," IEEE Trans. Power Delivery, vol. 18, July 2003.

[3] W. W. Price, K. A. Wirgau, A. Murdoch, J. V. Mitsche, E. Vaahedi, and M. A. El-Kady, "Load modeling for power flow and transient stability computer studies," IEEE Trans. on Power Systems, vol. 3, pp., $180-187,1988$.

[4] E. Vaahedi, H. M. Zein El-Din, and W. W. Price, "Dynamic load modeling in large scale stability studies," IEEE Trans. on Power Systems, vol. 3, $1039-1045,1988$.

[5] N. Mithulananthan, M. M. A. Salama, C. A. Can izares and J. Reeve, "Distribution system voltage regulation and var compensation for different static load models," International Journal of Electrical Engineering Education, 37/4. p.p 385-395, 2000.

[6] L. Shi, A. Meintz, and M. Ferdowsi, "Single-Phase Bidirectional ACDC Converters for Plug-in Hybrid Electric Vehicle Applications," in Proc.2008 IEEE Vehicle Power and Propulsion Conference.

[7] F. Marra, C. Træholt, E. Larsen and Q. Wu, "Average Behavior of Battery-Electric Vehicles for Distributed Energy Studies," in Proc.2010 IEEE Innovative Smart Grid Technologies.

[8] K. P. Schneider, J. C. Fuller, and D. P. Chassin "Multi-State load models for distribution system analysis," IEEE Trans. on power systems, vol. 26, pp. $2425-2433,2011$.

[9] K. Clement-Nyns, E. Haesen, and J. Driesen, "The impact of charging plug-in hybrid electric vehicles on a residential distribution grid," IEEE Trans. on Power Systems, Vol. 25, pp. 371 - 380, 2010.

[10] E. Sortomme, M. Hindi, S. D. J. MacPherson, and S. S. Venkata, "Coordinated charging of plug-in hybrid electric vehicles to minimize distribution system losses," IEEE Trans. on Smart Grid, vol. 2, pp. 198 $-205,2011$.

[11] N. Rotering, and M. Ilic, "Optimal charge control of plug-in hybrid electric vehicles in deregulated electricity markets," IEEE Trans. on Power Systems, vol. 26, No. 3, pp. 1021-1029, 2011.

[12] L. P. Fernandez, T. G. Roman, R. Cossent, C. M. Domingo, and P. Frias, "Assessment of the impact of plug-in electric vehicles on distribution networks," IEEE Trans. on Power Systems, vol. 26, pp. $206-213,2011$.

[13] K. Dyke, N. Schofield, and M. Barnes, "The impact of transport electrification on electrical networks," IEEE Trans. on Industrial Electronics, vol. 57, pp. 3917 - 3926, 2010.
[14] M. C. Kisacikoglu, B. Ozpineci, and L. M. Tolbert, "Reactive Power Operation Analysis of a Single-Phase EV/PHEV Bidirectional Battery Charger," in Proc.2011 8th International Conference on Power Electronics - ECCE Asia.

[15] F. Musavi, W. Eberle and W. G. Dunford, "A High-Performance Single-Phase Bridgeless Interleaved PFC Converter for Plug-in Hybrid Electric Vehicle Battery Chargers", IEEE Trans. on Industry Applications, Vol. 47, No. 4, July/August 2011.

[16] M. Yilmaz, and P. T. Krein, "Review of Battery Charger Topologies, Charging Power Levels, and Infrastructure for Plug-In Electric and Hybrid Vehicles," IEEE Trans. on Power Electronics, Vol. 28, No. 5, May 2012.

[17] M. Pahlevaninezhad, P. Das, J. Drobnik, P. K. Jain and A. Bakhshai, "A Novel ZVZCS Full-Bridge DC/DC Converter Used for Electric Vehicles," IEEE Trans. on Power Electronics, Vol. 27, No. 6, June 2012.

[18] R. Oruganti, and M. Palaniapan, "Inductor Voltage Control of BuckType Single-Phase AC-DC Converter," IEEE Trans. on Power Electronics, Vol. 15, No. 2, March 2000.

[19] S. Jaganathan and W. Gao, "Battery Charging Power Electronics Converter and Control for Plug-in Hybrid Electric Vehicle", in Proc. 2009 IEEE Vehicle Power and Propulsion.

[20] T. Tanaka, T. Sekiya, H. Tanaka, M. Okamoto, and E. Hiraki, "Smart Charger for Electric Vehicles With Power-Quality Compensator on Single-Phase Three-Wire Distribution Feeders", IEEE Trans. on Industry Applications, Vol. 49, No. 6, November/December 2013.

[21] Jung-Hyo Lee, Doo-Yong Jung, Sang-Hoon Park, Taek-Kie Lee, Young-Ryul Kim and Chung-Yuen Won "Battery Charging System for PHEV and EV using Single Phase AC/DC PWM Buck Converter," Journal of Electrical Engineering \& Technology Vol. 7, No. 5, pp. 736-744, 2012.

[22] B. Singh, B. N. Singh, A. Chandra, K. Al-Haddad, A. Pandey, and D. P. Kothari, “ A Review of Single-Phase Improved Power Quality ACDC Converters," IEEE Trans. on Industrial Electronics, Vol. 50, No. 5, October 2003.

[23] F. Musavi, M. Edington, W. Eberle, and W. G. Dunford, "Evaluation and Efficiency Comparison of Front End AC-DC Plug-in Hybrid Charger Topologies," IEEE Trans. on Smart Grid, Vol. 3, No. 1, March 2012.

[24] H. Chen, X. Wang, A. Khaligh, "A Single Stage Integrated Bidirectional AC/DC and DC/DC Converter for Plug-In Hybrid Electric Vehicles," in Proc. 2011 IEEE Vehicle Power and Propulsion.

[25] D. Gautam, F. Musavi, M. Edington W. Eberle, W. G. Dunford, “An Automotive On Board $3.3 \mathrm{~kW}$ Battery Charger for PHEV Application," in Proc. 2011 IEEE Vehicle Power and Propulsion.

[26] B. Savage, R. Shuttle worth, N. Schofield, "A Modular Battery Charger for Electric Vehicles," in Proc. 2013 IEEE Energy Conversion Congress and Exposition.

[27] R. Zhang, M. Cardinal, P. Szczesny and M. Dame, "A Grid Simulator with Control of Single-phase Power Converters in D-Q Rotating Frame," in Proc. 2002 IEEE on Power Electronics Specialists.

[28] Buchmann, (2014, Jan.). "Battery University: Charging Lithium-ion," Cadex Electronics Inc., [Online]. Available:http://batteryuniversity.com/learn/article/charging_lithium_i on_batteries.

[29] Ahmed M. A. Haidar, Kashem M. Muttaqi, Danny Soetanto, "Technical Challenges for Electric Power Industries due to GridIntegrated Electric Vehicles in Low Voltage Distributions: A review," Energy Conversion and Management, to be published.

[30] O. Tremblay, Louis-A. Dessaint, "Experimental Validation of a Battery Dynamic Model for EV Applications," World Electric Vehicle Journal Vol. 3, 2009.

[31] W. Zhang, G. Feng, Yan-Fei Liu, "A Direct Duty Cycle Calculation Algorithm for Digital Power Factor Correction (PFC) Implementation," in Proc. 2004 IEEE Power Electronics Specialists.

[32] L. M. Hajagos, B. Danai, "Laboratory Measurements and Models of Modem Loads and Their Effect on Voltage Stability Studies," IEEE Transactions on Power Systems, Vol. 13, No. 2, 1998.

[33] M. E. Baran and F. F. Wu, "Optimal capacitor placement on radial distribution systems," IEEE Transactions on Power Delivery, Vol. 4, No. 1, pp. 725-734, Jan 1989, 